\title{
Sugar-sweetened beverage intake and overweight in children from a Mediterranean country
}

\author{
Hugo Valente ${ }^{1,2, *}$, Vitor Teixeira ${ }^{1}$, Patricia Padrão ${ }^{1}$, Mariana Bessa $^{1}$, Tânia Cordeiro ${ }^{1}$, \\ André Moreira ${ }^{3,4}$, Vanessa Mitchell ${ }^{5}$, Carla Lopes ${ }^{6}$, Jorge Mota ${ }^{2,7}$ and \\ Pedro Moreira ${ }^{1,2}$ \\ ${ }^{1}$ Faculty of Nutrition and Food Sciences, University of Porto, Rua Dr. Roberto Frias, 4200-465 Porto, Portugal: \\ ${ }^{2}$ Research Centre in Physical Activity, Health and Leisure, University of Porto, Porto, Portugal: ${ }^{3}$ Faculty of \\ Medicine, Department of Immunology, University of Porto, Porto, Portugal: ${ }^{4}$ Department of Immunoallergology, \\ University Hospital of São João, Porto, Portugal: ${ }^{5}$ Department of Psychology, Glasgow Caledonian University, \\ Glasgow, UK: ${ }^{6}$ Department of Hygiene and Epidemiology, University of Porto Medical School, Porto, Portugal: \\ ${ }^{7}$ Faculty of Sport Sciences and Physical Education, University of Porto, Porto, Portugal
}

Submitted 30 December 2009: Accepted 14 July 2010: First published online 5 0ctober 2010

\begin{abstract}
Objective: To assess the association between sugar-sweetened beverage (SSB) consumption and overweight in children from a Mediterranean country.

Design: The children's dietary intake was measured using a semi-quantitative FFQ completed by the parents. Overall, 2512 questionnaires were returned and 837 children were removed, leaving a final sample of 1675 children, aged between 5 and 10 years. Height and weight were measured according to international standards, and BMI was calculated. The definition of overweight and obesity was based on average centiles according to the International Obesity Task Force cutoffs. To determine the magnitude of the association between SSB consumption and overweight, OR estimates, including CI, were computed using unconditional logistic regression, adjusting for confounders.

Setting: Elementary schools throughout the city of Porto, Portugal.

Subjects: We invited 5867 children, randomly selected, and their parents to participate in the study. Of those schools that agreed to take part, 3391 parents signed and returned the fully filled out consent form.

Results: The prevalence of overweight (including obesity) was $36 \cdot 6 \%$ for girls and $38.8 \%$ for boys. With regard to SSB consumption (serving/d), no differences between with overweight and non-overweight children were found even after adjustment for confounders (1-2 servings/d: OR $=1 \cdot 67,95 \%$ CI $0 \cdot 76,3 \cdot 66$, in girls; $\mathrm{OR}=1 \cdot 63,95 \% \mathrm{CI} 0 \cdot 76,3 \cdot 47$, in boys; and $>2$ servings $/ \mathrm{d}: \mathrm{OR}=0 \cdot 63,95 \%$ CI $0 \cdot 33,1 \cdot 22$, in girls; OR $=0 \cdot 64,95 \%$ CI $0 \cdot 33,1 \cdot 52$, in boys).

Conclusions: The intake of SSB was not associated with increased risk of overweight in Portuguese schoolchildren.
\end{abstract}

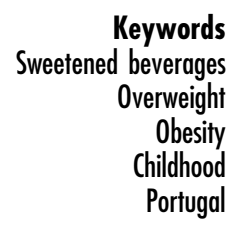

Overweight among children has increased dramatically in the last few years approaching epidemic proportions ${ }^{(1)}$ and various environmental, genetic and social factors have been associated with weight gain ${ }^{(2,3)}$. Recently, several epidemiological and experimental studies have linked the consumption of sugar-sweetened beverages (SSB), comprising soft drinks, iced tea, fruit juices and colas, to the rising rates of obesity and overweight ${ }^{(4-6)}$, and reported that regular SSB consumption from 2.5 to 4.5 years of age more than doubles the odds of being overweight at the age of 4.5 years, though this association remains controversial ${ }^{(7)}$ and some authors ${ }^{(8)}$ argue that energy compensation may not occur. It has been suggested by the WHO that the body may be unable to detect liquid energy as effectively as energy consumed in a solid form such that any subsequent energy adjustment is less precise ${ }^{(2)}$. Therefore, adding energy from fluids to the diet may lead to an increase in total energy intake as a result of inaccurate regulation of other energy sources. This has been documented for coffee, alcoholic beverages, fizzy drinks, fruit juice and milk ${ }^{(9)}$.

The studies ${ }^{(10-12)}$ that associate SSB intake and obesity are generally carried out in populations exposed to a Western dietary pattern of intake, characterized by high intake of fat, free sugars, refined grains, red meat, sugary desserts and high-sugar drinks ${ }^{(13)}$. None of the above-mentioned studies were carried out in a Mediterranean country. 
Considering that the different socio-economic and food environments in the studied populations may be important in the association between SSB intake and obesity, these relationships may vary according to specific factors related to the studied population, such as socio-economic background $^{(14)}$. Another of these characteristics may well be the global dietary pattern of intake, and studies on populations with diets that are distant from the Western dietary pattern, such as the Mediterranean diet, may provide valuable supplemental information. In the city of Porto, Portugal, the Mediterranean diet still represents an important pattern of food intake that may protect from chronic disease severity ${ }^{(15)}$.

The present study examined whether high SSB intake is associated with overweight in a sample of Mediterranean schoolchildren.

\section{Methods}

The data were derived from a community-based survey of children selected randomly from forty elementary schools, throughout the city of Porto, Portugal, of which thirty-five agreed to participate (thirty-five public schools with 5867 students). All schoolchildren's parents were invited to participate in the present study, of which 3391 accepted. After parental written consent was received, 2512 children's data sets were obtained. Each data set contained one FFQ regarding children's food intake and one sociodemographic questionnaire, both of which were asked to be filled out by their parents or tutors (the major responsible for their daily food intake). Children who were sick ( $n$ 3) and/or with incomplete questionnaires ( $n$ 242) were not included in the study. After dietary analysis, we excluded energy intake outliers ( $n 241 ;<3347 \mathrm{~kJ}(<800 \mathrm{kcal})$ and $>16736 \mathrm{~kJ}$ $(>4000 \mathrm{kcal})$ for boys, and $<2510(<600 \mathrm{kcal})$ and $>14644 \mathrm{~kJ}$ (>3500 kcal) for girls) ${ }^{(16)}$ and/or adolescents $(>10$ years old; $n$ 50) from the study. As many studies showed interesting results with SSB ingestion of $>1500 \mathrm{ml}^{(17)}$, we also assumed any student with a mean daily intake of SSB higher than $1500 \mathrm{ml}$ ( $n$ 301) as an outlier. The final sample included 1675 schoolchildren aged between 5 and 10 years.

Dietary intake was recorded using a semi-quantitative FFQ of the previous 12 months, comprising eighty-two food items or beverage categories and a frequency section with nine possible responses ranging from never to six or more times/d, developed by Lopes et ll $^{(18,19)}$. The FFQ was designed according to Willett ${ }^{(16)}$ and adapted by inclusion of a variety of typical Portuguese food items.

Nutrient intake data were obtained by multiplying the frequency of consumption of each food item by the nutrient content of the specified serving size, with once per day being equal to one. Seasonal variation of food consumption was also considered according to indications of participants on the average number of months of consumption per year. Energy and macronutrient intakes were estimated using an adapted Portuguese version of the nutritional analysis software Food Processor Plus (ESHA Research Inc., Salem, OR, USA). The analysis considered the intake of the SSB servings (three serving categories/d, such as $<1,1-3$ and $>3$; 1 serving size $=330 \mathrm{ml}$ ) derived from the FFQ.

Weight and height were measured in accordance with international standard methods for the collection of anthropometric data in children ${ }^{(20,21)}$. Weight was measured to the nearest $0.05 \mathrm{~kg}$ and height to the nearest $0 \cdot 1 \mathrm{~cm}$. Both measures were determined using a precision stadiometer (model 702; Seca, Hamburg, Germany) and taken in light clothing without shoes.

The weight status of the participants was also classified as recommended by the International Obesity Task Force, making a correspondence between the traditional adult cut-offs $\left(>25 \mathrm{~kg} / \mathrm{m}^{2}\right.$ to define overweight and $30 \mathrm{~kg} / \mathrm{m}^{2}$ to define obesity) and specific values for adolescents considering sex and age in complete and half years ${ }^{(22)}$.

The sociodemographic questionnaire contained information on the age of the children and the education of the parents, evaluated in years, using the following categories: $0,1-4,5-9,10-12$ and $>12$ years. For the purpose of the data analysis, these were collapsed into: up to 9, 10-12 and $>12$ years.

In order to assess the level of physical activity, the questionnaire included items regarding the time spent watching television (TV)/video and playing computer/ electronic games. Answers to each of these questions were divided into weekdays, Saturdays and Sundays, and for the category, these were further sub-divided into the following: $<1 \mathrm{~h}, 1-2 \mathrm{~h}, 2-4 \mathrm{~h}, 4-6 \mathrm{~h}$ and $>6 \mathrm{~h}$. Later, these variables were recoded for the analysis into: up to $1 \mathrm{~h} / \mathrm{d}$ and $\geq 1 \mathrm{~h} / \mathrm{d}$.

Statistical analysis was performed by the Statistical Package for Social Sciences statistical software package version $14 \cdot 0$ (SPSS Inc., Chicago, IL, USA) and the significance level was set at 5\%. OR estimates, including CI, were computed using binary logistic regression to estimate the association between SSB intake (considering three categories: $<1$ serving/d (reference category), 1-3 and $>3$ servings/d) and overweight. The adjustment considered variables that presented a statistically significant effect in univariate analysis and were considered to sustain a plausible biological and temporal relationship with the outcome (TV watching, sleep time, energy intake, parental education level, total carbohydrates, sugars, MUFA and questionnaire responder).

Throughout the paper, unless stated otherwise, it can be assumed that the overweight group also includes obese children.

\section{Results}

Girls showed higher percentages of overweight (25.8\%) than boys $(24.7 \%)$ and boys showed higher percentages of obesity $(14 \cdot 1 \%)$ than girls $(10 \cdot 8 \%)$. 
Table 1 Contributions to total energy intake and descriptive social factors by gender, weight and SSB intake

\begin{tabular}{|c|c|c|c|c|c|c|c|c|c|c|c|c|c|c|c|c|c|c|}
\hline & \multicolumn{9}{|c|}{ Girls ( $n$ 842) } & \multicolumn{9}{|c|}{ Boys ( $n$ 833) } \\
\hline & \multicolumn{5}{|c|}{ Overweight } & \multicolumn{4}{|c|}{ SSB intake (serving/d) } & \multicolumn{5}{|c|}{ Overweight } & \multicolumn{4}{|c|}{ SSB intake (serving/d) } \\
\hline & \multicolumn{2}{|c|}{ No } & \multicolumn{2}{|c|}{ Yes } & \multirow[b]{2}{*}{$P$} & \multirow[b]{2}{*}{ No } & \multirow[b]{2}{*}{$1-3$} & \multirow[b]{2}{*}{$>3$} & \multirow[b]{2}{*}{$P$} & \multicolumn{2}{|c|}{ No } & \multicolumn{2}{|c|}{ Yes } & \multirow[b]{2}{*}{$P$} & \multirow[b]{2}{*}{ No } & \multirow[b]{2}{*}{$1-3$} & \multirow[b]{2}{*}{$>3$} & \multirow[b]{2}{*}{$P$} \\
\hline & Mean & SD & Mean & SD & & & & & & Mean & SD & Mean & SD & & & & & \\
\hline Energy (kcal)* & 2239 & 559 & 2204 & 579 & 0.915 & 2138 & 2272 & 2446 & & 2367 & 578 & 2354 & 680 & $0 \cdot 777$ & 2251 & 2383 & 2561 & \\
\hline Energy (\%) & & & & & & & & & & & & & & & & & & \\
\hline Total carbohydrates & $51 \cdot 3$ & $6 \cdot 1$ & $51 \cdot 1$ & $5 \cdot 0$ & 0.600 & $50 \cdot 3$ & $51 \cdot 1$ & $53 \cdot 4$ & & $51 \cdot 3$ & $5 \cdot 7$ & $52 \cdot 3$ & $5 \cdot 2$ & 0.014 & $51 \cdot 0$ & $51 \cdot 9$ & $53 \cdot 1$ & \\
\hline Sugars & $23 \cdot 0$ & $5 \cdot 7$ & $23 \cdot 3$ & $5 \cdot 5$ & 0.433 & $21 \cdot 8$ & $22 \cdot 9$ & $26 \cdot 7$ & & $22 \cdot 9$ & $5 \cdot 3$ & $23 \cdot 9$ & $5 \cdot 4$ & 0.008 & $21 \cdot 8$ & $24 \cdot 3$ & $25 \cdot 8$ & \\
\hline Total fat & $32 \cdot 1$ & $4 \cdot 7$ & $32 \cdot 2$ & $4 \cdot 6$ & 0.779 & $32 \cdot 6$ & $32 \cdot 2$ & $31 \cdot 2$ & & $32 \cdot 0$ & $4 \cdot 4$ & $31 \cdot 5$ & $4 \cdot 1$ & 0.086 & 31.9 & $31 \cdot 7$ & 31.5 & \\
\hline SFA & $10 \cdot 7$ & 1.9 & $10 \cdot 7$ & $1 \cdot 8$ & 0.967 & $10 \cdot 8$ & $10 \cdot 5$ & $10 \cdot 4$ & & $10 \cdot 6$ & $2 \cdot 5$ & $10 \cdot 5$ & $1 \cdot 3$ & 0.599 & $10 \cdot 5$ & $10 \cdot 8$ & $10 \cdot 6$ & \\
\hline MUFA & $13 \cdot 6$ & $2 \cdot 6$ & $13 \cdot 6$ & $2 \cdot 7$ & $0 \cdot 707$ & $13 \cdot 9$ & $13 \cdot 6$ & $13 \cdot 1$ & & $13 \cdot 6$ & $2 \cdot 5$ & $13 \cdot 3$ & $2 \cdot 3$ & 0.035 & $13 \cdot 7$ & $13 \cdot 3$ & $13 \cdot 1$ & \\
\hline PUFA & $5 \cdot 2$ & $1 \cdot 1$ & $5 \cdot 2$ & $1 \cdot 0$ & 0.552 & $5 \cdot 2$ & $5 \cdot 4$ & $5 \cdot 2$ & & $5 \cdot 1$ & $1 \cdot 0$ & $5 \cdot 1$ & $1 \cdot 1$ & $0 \cdot 170$ & $5 \cdot 0$ & $5 \cdot 0$ & $5 \cdot 2$ & \\
\hline Protein & $18 \cdot 3$ & $2 \cdot 5$ & $18 \cdot 4$ & $2 \cdot 6$ & 0.889 & $18 \cdot 8$ & $18 \cdot 3$ & $17 \cdot 1$ & & $18 \cdot 3$ & $2 \cdot 6$ & $18 \cdot 0$ & $2 \cdot 5$ & $0 \cdot 102$ & $18 \cdot 7$ & $18 \cdot 1$ & $17 \cdot 1$ & \\
\hline & $\%$ & & \% & & & & & & & \% & & $\circ$ & & & & & & \\
\hline SSB intake (serving & & & & & & & & & & & & & & & & & & \\
\hline$<1$ & 64 & & 64 & & 0.68 & - & - & - & - & 57 & & 56 & & 0.585 & - & - & - & - \\
\hline $1-3$ & 10 & & 13 & & & - & - & - & - & 14 & & 14 & & & - & - & - & - \\
\hline$>3$ & 25 & & 22 & & & - & - & - & - & 27 & & 25 & & & - & - & - & - \\
\hline Mother's education & & & & & & & & & & & & & & & & & & \\
\hline$<9$ & 27 & & 28 & & 0.001 & $24 \cdot 8$ & $25 \cdot 5$ & $36 \cdot 8$ & 0.05 & 26 & & 26 & & 0.917 & $23 \cdot 7$ & $24 \cdot 8$ & $31 \cdot 7$ & 0.55 \\
\hline $9-12$ & 19 & & 29 & & & $22 \cdot 1$ & $27 \cdot 7$ & 23.9 & & 21 & & 20 & & & $20 \cdot 0$ & $27 \cdot 3$ & $21 \cdot 1$ & \\
\hline$>12$ & 53 & & 41 & & & $53 \cdot 1$ & $46 \cdot 8$ & $39 \cdot 3$ & & 52 & & 53 & & & $56 \cdot 3$ & $47 \cdot 9$ & $47 \cdot 1$ & \\
\hline Father's education ( & & & & & & & & & & & & & & & & & & \\
\hline$<9$ & 29 & & 30 & & 0.139 & $25 \cdot 7$ & $19 \cdot 3$ & $39 \cdot 3$ & 0.012 & 30 & & 32 & & 0.009 & $28 \cdot 0$ & $30 \cdot 4$ & $37 \cdot 1$ & 0.002 \\
\hline $9-12$ & 23 & & 28 & & & $27 \cdot 1$ & 23.9 & $23 \cdot 0$ & & 18 & & 26 & & & $19 \cdot 4$ & $22 \cdot 6$ & $26 \cdot 6$ & \\
\hline$>12$ & 47 & & 41 & & & $47 \cdot 2$ & $46 \cdot 7$ & $37 \cdot 0$ & & 51 & & 40 & & & $52 \cdot 6$ & $47 \cdot 0$ & $36 \cdot 2$ & \\
\hline TV watching $(\mathrm{h})$ & & & & & & & & & & & & & & & & & & \\
\hline Weekdays & & & & & & & & & & & & & & & & & & \\
\hline$<1$ & 44 & & 39 & & 0.013 & $44 \cdot 5$ & $39 \cdot 1$ & $29 \cdot 5$ & 0.01 & 48 & & 41 & & 0.04 & $48 \cdot 5$ & $45 \cdot 0$ & $39 \cdot 9$ & $0 \cdot 102$ \\
\hline$\geq 1$ & 26 & & 60 & & & $55 \cdot 5$ & $60 \cdot 9$ & $70 \cdot 5$ & & 51 & & $5 \varepsilon$ & & & 51.5 & $55 \cdot 0$ & $60 \cdot 1$ & \\
\hline Saturday & & & & & & & & & & & & & & & & & & \\
\hline$<1$ & 9 & & 6 & & 0.227 & $53 \cdot 7$ & $44 \cdot 7$ & $46 \cdot 6$ & 0.098 & 8 & & & & 0.801 & $59 \cdot 3$ & $48 \cdot 8$ & $49 \cdot 6$ & 0.017 \\
\hline$\geq 1$ & 90 & & 93 & & & $46 \cdot 3$ & $55 \cdot 7$ & $53 \cdot 4$ & & 91 & & 90 & & & $40 \cdot 7$ & $51 \cdot 2$ & $50 \cdot 4$ & \\
\hline Sunday & & & & & & & & & & & & & & & & & & \\
\hline$<1$ & 10 & & 9 & & $0 \cdot 712$ & $52 \cdot 4$ & $42 \cdot 1$ & $46 \cdot 6$ & $0 \cdot 106$ & 8 & & & & $0 \cdot 847$ & $56 \cdot 0$ & $45 \cdot 8$ & $47 \cdot 1$ & 0.031 \\
\hline$\geq 1$ & 90 & & 90 & & & $47 \cdot 6$ & $57 \cdot 9$ & $53 \cdot 4$ & & 91 & & 91 & & & $44 \cdot 0$ & $54 \cdot 2$ & $52 \cdot 9$ & \\
\hline Questionnaire respo & & & & & & & & & & & & & & & & & & \\
\hline Father & 17 & & 18 & & 0.857 & $17 \cdot 4$ & $16 \cdot 7$ & $18 \cdot 4$ & $0 \cdot 881$ & 18 & & 16 & & 0.368 & $16 \cdot 3$ & $18 \cdot 5$ & $18 \cdot 8$ & 0.894 \\
\hline Mother & 80 & & 78 & & & $80 \cdot 1$ & $82 \cdot 3$ & $78 \cdot 7$ & & 70 & & 80 & & & $81 \cdot 1$ & $78 \cdot 2$ & $78 \cdot 2$ & \\
\hline Others & 2 & & 2 & & & $2 \cdot 4$ & $1 \cdot 0$ & 2.9 & & 2 & & & & & $2 \cdot 5$ & $3 \cdot 2$ & $3 \cdot 1$ & \\
\hline
\end{tabular}

SSB, sugar-sweetened beverages; TV, television.

Student's $t$ test and Mann-Whitney $U$ test were used to compare nutritional variables according to overweight status and SSB intake, in each gender; for other variables, $\chi^{2}$ tests were used to estimate their association

according to overweight status and SSB intake, in each gender.
${ }^{1} \mathrm{kcal}=4 \cdot 184 \mathrm{~kJ}$. 
Table 2 Association between overweight and SSB consumption

\begin{tabular}{|c|c|c|c|c|c|c|c|c|}
\hline & \multicolumn{4}{|c|}{ Girls (n 842) } & \multicolumn{4}{|c|}{ Boys ( $n$ 833) } \\
\hline & Crude OR & $95 \% \mathrm{Cl}$ & Adjusted OR & $95 \% \mathrm{Cl}$ & Crude OR & $95 \% \mathrm{Cl}$ & Adjusted OR & $95 \% \mathrm{Cl}$ \\
\hline \multicolumn{9}{|c|}{ SSB intake (serving/d) } \\
\hline$<1$ & $1 \cdot 00$ & Ref. & $1 \cdot 00$ & Ref. & 1.00 & Ref. & 1.00 & Ref. \\
\hline $1-3$ & $1 \cdot 24$ & $0.79,3.66$ & 1.67 & $0.76,3.66$ & 0.98 & $0.65,1.5$ & $1 \cdot 63$ & $0.76,3.47$ \\
\hline$\geq 3$ & 0.87 & $0.62,1.23$ & 0.63 & $0.33,1.22$ & 1.06 & $0.77,1.47$ & 0.64 & $0.33,1.52$ \\
\hline
\end{tabular}

SSB, sugar-sweetened beverages; Ref., reference category.

Binary logistic regression analysis adjusting for energy intake, parents' education level, time of sleep, questionnaire responder, total carbohydrates, sugars, MUFA and television watching.

Energy intake was not significantly different between overweight and non-overweight children. Regarding the percentage contributions to total energy intake (Table 1), no differences were found between normal and overweight girls; however, significantly higher mean intakes of total carbohydrates $(52 \cdot 3 v .51 \cdot 2 \%, P=0 \cdot 014)$ and sugars (23.9 v. 22.9\%, $P=0.008$ ) were found in overweight boys, compared with normal-weight boys. In contrast, overweight boys presented significantly lower contributions of MUFA (13.3 v. 13.6\%, $P=0 \cdot 035)$.

Parents of non-overweight girls had a higher education level than those of overweight girls, but in boys we found that the overweight group had mothers with higher education levels than those in the non-overweight group. Significant statistical differences in overweight and nonoverweight children were found by the girl's mother's education level $(P=0 \cdot 001)$ and the boy's father's education level $(P=0 \cdot 009)$.

Overweight children spent more time watching TV, but significant results were found only on weekdays ( $P=0.042$ for girls and $P=0.036$ for boys).

Table 1 shows different distributions between the children's SSB intake (categories of the intake of SSB servings $/ \mathrm{d})$ and mother's education $(P=0 \cdot 050)$, father's education $(P=0 \cdot 012)$ and TV watching on weekdays $(P=0 \cdot 010)$ in girls, and father's education $(P=0 \cdot 002)$, TV watching during Saturday $(P=0 \cdot 017)$ and TV watching during Sunday $(P=0 \cdot 031)$ in boys.

We did not find any association between overweight and SSB consumption (Table 2) in any consumption group even after adjustment for TV watching, sleep time, energy intake, parental education level, total carbohydrates, sugars, MUFA and questionnaire responder (1-2 servings $/ \mathrm{d} v \cdot<1$ serving/d: $\mathrm{OR}=1 \cdot 67,95 \% \mathrm{CI} 0 \cdot 76,3 \cdot 66$ in girls and OR $=1 \cdot 63,95 \%$ CI 0.76, $3 \cdot 47$ in boys; and $>2$ servings/d $v .<1$ serving/d: $\mathrm{OR}=0 \cdot 63,95 \% \mathrm{CI} 0 \cdot 33,1 \cdot 22$ in girls and $\mathrm{OR}=0 \cdot 64,95 \% \mathrm{CI} 0 \cdot 33,1.52$ in boys).

\section{Discussion}

Beverages can play an important role in energy intake due to the evidence that high intake of liquid carbohydrates may lead to weight gain because of a lack of dietary compensation compared to that observed in similar amounts of solid carbohydrates $^{(23)}$. This SSB association with overweight in children found in some studies from other countries ${ }^{(10,24)}$ was not supported in our study.

We did not find any association between SSB and overweight, for both genders, even after statistical adjustment for potential confounders. Although findings from some cross-sectional ${ }^{(25,26)}$ studies suggest a positive trend in the relationship between SSB intake and obesity, meta-analysis $^{(17)}$ failed to find such an association. Controversy between studies may arise from different instruments to measure SSB consumption, different measures of weight gain, different statistical models to estimate the effect sizes and different units of time. Indeed, Drewnowski et al. ${ }^{(14)}$ suggest that the socio-economic environment should be taken into account as a factor of SSB intake, and not only with its isolated ingestion. Nevertheless, even after adjustment for these potential confounders in our study, no significant association was found between SSB and overweight.

In our study, parents were interviewed and reported on the consumption patterns of their children, and although this data collection method does not rely on children's memory, it may be associated with bias due to lack of parental knowledge of children's eating habits (particularly on food eaten away from home), inability to estimate exact serving sizes and frequency of consumption and the possibility of a differential recall bias by parents across children's weight status categories ${ }^{(27)}$.

One discussion point in the present study could be the inclusion of all SSB (colas, iced teas and fruit juices) in the same analysis group. This decision was based on our previous data ${ }^{(28)}$ in which no effect of isolated SSB consumption (colas, iced teas and fruit juices) on weight was found. The intake of each SSB per se was probably not enough to show any effect on children's weight.

Another perspective could be that regular overweight SSB consumers may unwittingly be consuming more sweetened beverages than reported. Likewise, parents of overweight children may be under-reporting their children's intake of $\mathrm{SSB}^{(27)}$, and these factors may also explain the lack of evidence in our study.

Our findings indicate a higher prevalence of overweight in children from both genders than do recent Portuguese data ${ }^{(29)}$. Our findings also show a higher prevalence of overweight in children from both genders, 
especially in boys $(38.8 \%)$. This high value supports the urgency of a nutritional intervention for Portuguese schoolchildren, namely using education programmes in school, parents' education and control of the contents of school vending machines. At the macronutrient level, high intakes of fat and protein, and a low intake of carbohydrates, regarding WHO recommendations ${ }^{(2)}$, seem to be one of the causes of the growing levels of overweight.

Our results also suggest that overweight children spend more time watching TV than do normal-weight children, for both genders. According to the American Academy of Pediatrics, children's total media time (with entertainment media) should not be higher than $1-2 \mathrm{~h} / \mathrm{d}^{(30)}$, and children exposed to TV viewing for more than $1 \mathrm{~h} / \mathrm{d}$ may already be at increased risk for overweight ${ }^{(28)}$. $\mathrm{WHO}^{(2)}$ classifies high dietary fibre intake and regular physical activity as convincing factors to protect against weight gain, and therefore these two factors should be the major focus base of any planned intervention in children.

To the best of our knowledge, this is the first study to describe that high SSB intake is not associated with overweight in a sample of Mediterranean schoolchildren. Our findings suggest that reducing or eliminating SSB consumption would not have a large effect on the BMI distribution of children. Therefore, dietary advice and education should clearly communicate that SSB should only be consumed in moderation as part of a balanced diet, especially for those children who are overweight or at risk of becoming overweight, because SSB still are a source of energy.

Future research should also try to evaluate whether high SSB intake is related to other food intake patterns so that we could have better knowledge of the role of SSB and children's obesity.

\section{Acknowledgements}

The present study was supported by a scholarship from Nestle Portugal SA. The authors declare that they have no conflict of interest. H.V. supervised all aspects of the study implementation, conducted statistical analyses and wrote the paper. V.T., P.P., A.M., V.M., C.L. and J.M. helped to interpret the findings and review the drafts of the manuscript. M.B. and T.C. helped to review the drafts of the manuscript. P.M. designed the study, supervised all aspects of its implementation, conducted the statistical analyses and helped to interpret the findings and review the drafts of the manuscript.

\section{References}

1. World Health Organization (2004) WHO global strategy on diet, physical activity and health - what are the challenges for follow-up in Europe?: Workshop 1. Eur J Public Health 14, Suppl. 1, 8.
2. World Health Organization (2003) Diet, Nutrition and the Prevention of Chronic Diseases. World Health Organization Technical Report Series no. 916. Geneva: WHO.

3. Dubois L \& Girard M (2006) Early determinants of overweight at 4.5 years in a population-based longitudinal study. Int J Obes (Lond) 30, 610-617.

4. Schulze MB, Manson JE, Ludwig DS et al. (2004) Sugarsweetened beverages, weight gain, and incidence of type 2 diabetes in young and middle-aged women. JAMA 292, 927-934.

5. Welsh JA, Cogswell ME, Rogers S et al. (2005) Overweight among low-income preschool children associated with the consumption of sweet drinks: Missouri, 1999-2002. Pediatrics 115, e223-e229.

6. Berkey CS, Rockett HR, Field AE et al. (2004) Sugar-added beverages and adolescent weight change. Obes Res 12, 778-788.

7. Dubois L, Farmer A, Girard M et al. (2007) Regular sugarsweetened beverage consumption between meals increases risk of overweight among preschool-aged children. J Am Diet Assoc 107, 924-934.

8. Johnson L, Mander AP, Jones LR et al. (2007) Is sugarsweetened beverage consumption associated with increased fatness in children? Nutrition 23, 557-563.

9. Mattes R (2006) Fluid calories and energy balance: the good, the bad, and the uncertain. Physiol Behav 89, 66-70.

10. Ludwig DS, Peterson KE \& Gortmaker SL (2001) Relation between consumption of sugar-sweetened drinks and childhood obesity: a prospective, observational analysis. Lancet 357, 505-508.

11. Blum JW, Jacobsen DJ \& Donnelly JE (2005) Beverage consumption patterns in elementary school aged children across a two-year period. J Am Coll Nutr 24, 93-98.

12. Newby PK, Peterson KE, Berkey CS et al. (2004) Beverage consumption is not associated with changes in weight and body mass index among low-income preschool children in North Dakota. J Am Diet Assoc 104, 1086-1094.

13. Pereira M (2006) The possible role of sugar-sweetened beverages in obesity etiology: a review of the evidence. Int J Obes (Lond) 30, S28-S36.

14. Drewnowski A \& Bellisle F (2007) Liquid calories, sugar, and body weight. Am J Clin Nutr 85, 651-661.

15. Barros R, Moreira A, Fonseca J et al. (2008) Adherence to the Mediterranean diet and fresh fruit intake are associated with improved asthma control. Allergy 63, 917-923.

16. Willett W (1998) Nutritional Epidemiology, 2nd ed. New York: Oxford University Press.

17. Forshee RA, Anderson PA \& Storey ML (2008) Sugarsweetened beverages and body mass index in children and adolescents: a meta-analysis. Am J Clin Nutr 87, $1662-1671$.

18. Lopes C (2000) Reproducibility and validation of a semiquantitative food-frequency questionnaire. In Diet and Acute Myocardial Infarction: A Population-Based CaseControl Study, pp. 79-115. Porto: University of Porto.

19. Lopes C, Aro A, Azevedo A et al. (2007) Intake and adipose tissue composition of fatty acids and risk of myocardial infarction in a male Portuguese community sample. $J \mathrm{Am}$ Diet Assoc 107, 276-286.

20. World Health Organization (1995) Physical Status: The Use and Interpretation of Anthropometry. Geneva: WHO.

21. World Health Organization (1995) An evaluation of infant growth: the use and interpretation of anthropometry. Bull World Health Organ 73, 165-174.

22. Cole TJ, Bellizzi MC, Flegal KM et al. (2000) Establishing a standard definition for child overweight and obesity worldwide: international survey. BMJ 320, 1240-1243. 
23. DiMeglio DP \& Mattes RD (2000) Liquid versus solid carbohydrate: effects on food intake and body weight. Int J Obes Relat Metab Disord 24, 794-800.

24. Sanigorski AM, Bell AC \& Swinburn BA (2007) Association of key foods and beverages with obesity in Australian school children. Public Health Nutr 10, 152-157.

25. Ariza AJ, Chen EH, Binns HJ et al. (2004) Risk factors for overweight in five- to six-year-old Hispanic-American children: a pilot study. J Urban Health 81, 150-161.

26. Andersen LF, Lillegaard IT, Overby N et al. (2005) Overweight and obesity among Norwegian school children: changes from 1993 to 2000. Scand J Public Health 33, 99-106.
27. Livingstone MB, Robson PJ \& Wallace JM (2004) Issues in dietary intake assessment of children and adolescents. Br J Nutr 92, Suppl. 2, S213-S222.

28. Bessa $\mathrm{M}$, Valente $\mathrm{H}$, Cordeiro $\mathrm{T}$ et al. (2008) Ingestão de alimentos fluidos e risco de excesso de peso em crianças (Fluid intake and overweight risk in children). Acta Med Port 21, 161-170.

29. Padez C, Fernandes T, Mourao I et al. (2004) Prevalence of overweight and obesity in 7-9-year-old Portuguese children: trends in body mass index from 1970-2002. Am J Hum Biol 16, 670-678.

30. Walsh DA \& Gentile DA (2001) A validity test of movie, television, and video-game ratings. Pediatrics 107, 1302-1308. 